RESEARCH ARTICLE

\title{
Transobturator Tape: A Gold Standard for Stress Urinary Incontinence
}

\author{
Anuja Bhalerao ${ }^{1}$, Neha V Harne ${ }^{2}$, Krutika V Bhalerao ${ }^{3}$
}

\begin{abstract}
Objective: The objective of this paper is to evaluate the effectiveness of the transobturator vaginal tape (TOT) in the management of female stress urinary incontinence (SUI) and to analyze complications after 6 months of follow-up.

Materials and methods: The study included women with SUI who had a TOT procedure in which the sling passes from the obturator foramen from outside to the inside, under regional anesthesia from January 2013 to December 2015. All women had a minimal follow-up of 6 months. The women were prospectively evaluated, and assessment was done by physical examination including pelvic examination, urinalysis, the cough stress test, and the Bonney's test.

Results: Twenty-two consecutive women who fulfilled the inclusion criteria underwent the TOT procedure by a single surgeon. The mean age was $44.8 \pm 4.2$ years (range 37-53 years) and minimal follow-up was 6 months. The mean operative time was $25 \pm 5$ minutes (range 15-31 minutes), with an average amount of blood loss in all cases. Our results demonstrate a $90.90 \%$ cure or improvement rate after 6 months.

Conclusion: The transobturator approach from outside to inside is an effective modality of treating SUI with low morbidity. However, longer follow-up in larger populations is needed to assess the reliability of this procedure.

Keywords: Stress urinary incontinence, Tension free, Transobturator tape.

Journal of South Asian Federation of Menopause Societies (2019): 10.5005/jp-journals-10032-1192
\end{abstract}

\section{INTRODUCTION}

Stress urinary incontinence (SUI) impairs the quality of life for many women leading to impaired socialization, psychological distress, and urinary tract infections (UTIs). About 50\% of women with urinary incontinence report symptoms of stress incontinence; longitudinal studies assessing the natural history of stress incontinence provided an annual incidence of 4-10\%. ${ }^{1}$ Stress urinary incontinence is defined as involuntary urine leakage on effort or exertion (e.g., on sneezing or coughing) without rise in detrusor pressure. ${ }^{2}$ A large meta-analysis reported a prevalence of SUI to be $30 \%$ in women aged 30-60 years, with approximately half of the cases attributed to SUI. ${ }^{3}$

The minimally invasive synthetic mid-urethral sling (MUS) (transvaginal tape or TVT) has become the preferred surgical method for the treatment of female SUI since its introduction in 1995 by Ulmsten et al. ${ }^{4}$ Inspite of its minimally invasive nature and good success rates, the blind passage of trocars along the retro pubic route for placement of this sling is known to cause inadvertent vesical injury and life-threatening complications such as injury to the iliac vessels and bowel.

The transobturator route (outside-in) for the treatment of SUI was developed by Delorme in $2001^{5}$ to reduce complications of TVT. This sling and its modification as the inside-out technique by de Leval in $2003^{6}$ achieved widespread acceptance.

Surgical treatment of SUI has changed drastically over years. Previously autologous fascial pubovaginal slings were used as standard treatment for SUI but currently the most favored treatment for SUI is MUS. The commonest type of MUS used today is the one traversing the transoburator route. This approach is theoretically advantageous with less obstruction and postoperative voiding dysfunction and prevents bladder and bowel perforation. Subsequently, De Tayrac reported a 1-year cure rate of $84 \%$ with the

\footnotetext{
${ }^{1-3}$ Department of Obstetrics and Gynaecology, NKP Salve Institute of Medical Sciences and Research Centre and Lata Mangeshkar Hospital, Nagpur, Maharashtra, India

Corresponding Author: Neha V Harne, Department of Obstetrics and Gynaecology, NKP Salve Institute of Medical Sciences and Research Centre and Lata Mangeshkar Hospital, Nagpur, Maharashtra, India, Phone: +91 9405302251, e-mail: nehaharne081192@gmail.com

How to cite this article: Bhalerao A, Harne NV, Bhalerao KV. Transobturator Tape: A Gold Standard for Stress Urinary Incontinence. J South Asian Feder Menopause Soc 2019;7(2):86-89.

Source of support: Nil

Conflict of interest: None
}

transobturator vaginal tape (TOT) procedure. ${ }^{7}$ This study is done as there is paucity of Indian data regarding its use and effectiveness.

\section{Objectives}

- To evaluate the subjective cure, defined by the patient herself as absence or improvement in SUI symptoms.

- To assess the objective cure by noting intraoperative and postoperative adverse events, need for repeat incontinence procedures, and the quality of life.

\section{Materials and Methods}

This prospective hospital-based study was conducted in the department of obstetrics and gynecology, at a tertiary care ruralbased medical college and hospital for a duration of 3 years from January 2013 to December 2015 after obtaining ethics committee approval. 
All women who came with complaints of SUI were subjected for detailed history pertaining to demographic data, urogynecological history, obstetric history, family history, past, and personal history. All women were systematically examined for stress incontinence and to rule out any other associated pelvic pathology. The cough stress test was done for documentation of SUI and the Bonney's test was done to decide for surgical management.

\section{Inclusion Criteria}

- All women in the age group of 30-60 years with SUI affecting day-to-day life

- Hypermobile urethra

- Willing for surgery

- Willing for follow-up

\section{Exclusion Criteria}

- Associated urge incontinence

- Pregnancy

- History of previous surgery

- Neurogenic bladder

Women after preoperative assessment were subjected for a MUS via the transobturator route by the outside-in technique. The needles and polypropylene tape used were of the same brand. Women with prolapse and SUI underwent a hysterectomy and pelvic floor reconstruction with TOT. The time taken for the surgical procedure was noted for every patient. The blood loss at the time of surgery was assessed.

Postoperative analgesia was given as per demand, based on amount of pain, and the women were discharged when they had passed urine. The period of their hospital stay was noted. Women were advised at the time of discharge, which specifically stressed to avoid squatting and intercourse for 4 weeks and they were called for a follow-up at 4 weeks after surgery and then at 3 and 6 months.

At the postoperative visits, all women were evaluated with history, examination, and validated questionnaire. Perioperative complications, including bladder injury, groin pain, voiding difficulties, and subjective feeling of incomplete bladder emptying, were catheterized and followed-up till residual urine was less than $100 \mathrm{~mL}$. The long-term postoperative complications that were looked for were tape erosion, recurrent UTI, dyspareunia, and urinary urgency.

Subjective improvement was defined by patient satisfaction, which was graded as complete satisfaction/partial satisfaction/ nonsatisfied. Objective cure was defined by the negative cough stress test and the negative pad test.

All these accumulated data were statistically analyzed using appropriate statistical techniques.

\section{Results}

From January 2013 to December 2014, 22 women with SUI attended the gynecological outpatient department of a tertiary care hospital. A total of 18 (81.81\%) women belonged to the age group of 40-49 years. A total of 11 women were postmenopausal and all were multiparous.

A total of 22 women with SUI fulfilled the inclusion criteria. The mean age was 44.8 years (range $37-58$ years) The mean operative time was $25 \pm 5$ minutes (range 15-31 minutes) with intraoperative amount of bleeding being average (less than $50 \mathrm{cc}$ ) and the minimal follow-up was 6 months (Tables 1 to 6 ).

None of the women had excessive bleeding during surgery. Lateral vaginal injury was encountered in one patient, which was identified at the time of the injury and corrected timely. Urinary tract infection occurred in six women (27.27\%) and were managed with oral antibiotics. Four women (18.18\%) developed transient urinary retention after the removal of the catheter; the next day the women had normal void. One women had erosion (tape) vaginally. None of the women experienced bladder or urethral injury. The overall satisfaction rate was $90.90 \%$. Postoperative urinary complications encountered with the TOT were a sense of incomplete voiding of urine but there was no significant difference in residual post-void volumes when we compared preoperative values with those at 6 months. Groin pain was seen in three (13.64\%) women and four (18.18\%) women had dyspareunia.

The subjective assessment demonstrated was $72.72 \%$ cure and 18.18\% improvement after 6 months.

Our objective assessment demonstrated was $81.81 \%$ cure and 9.9\% improvement after 6 months (no apparent cause could be found for failure of surgery in these two cases).

Table 1: Baseline data and intraoperative and postoperative data of women with stress urinary incontinence

\begin{tabular}{ll}
\hline Variable & TOT $(n=22)$ \\
\hline Baseline data & \\
$\quad \begin{array}{l}\text { Age (years) } \\
\text { Parity }\end{array}$ & $44.8 \pm 4.2$ \\
$\quad \begin{array}{l}\text { Percentage of postmenopausal } \\
\text { patients }\end{array}$ & 41.6 \\
$\quad$ Duration of SUI (months) & $6-36$ \\
$\begin{array}{l}\text { Intraoperative data } \\
\text { Blood loss (cc) } \\
\quad \begin{array}{l}\text { Operative time (minutes) } \\
\text { Postoperative days with catheter } \\
\text { Hospital stay (days) }\end{array}\end{array}$ & $\begin{array}{l}\text { Average }(<50) \\
25 \pm 5(15-31)\end{array}$ \\
\hline
\end{tabular}

Table 2: Intraoperative and postoperative complications data of women with stress urinary incontinence

\begin{tabular}{ll}
\hline Complications & $n=22(\%)$ \\
\hline Bladder injury & $\mathrm{Nil}$ \\
Hemorrhage & $\mathrm{Nil}$ \\
Postoperative obstructive voiding & $4(18.18)$ \\
Long-term voiding symptoms & $3(13.64)$ \\
Urinary tract infection & $6(27.27)$ \\
Groin pain & $3(13.64)$ \\
Dyspareunia & $4(18.18)$ \\
Tape erosion & $1(4.54)$ \\
Vaginal laceration & $1(4.54)$ \\
\hline
\end{tabular}

Table 3: Subjective cure in women with stress urinary incontinence

\begin{tabular}{llll}
\hline Subjective cure & Cured & Improved & Failed \\
\hline Stress test & $16(72.72 \%)$ & $4(18.18 \%)$ & $2(9.9 \%)$ \\
Pad test & $16(72.72 \%)$ & $4(18.18 \%)$ & $2(9.9 \%)$ \\
\hline
\end{tabular}


Table 4: Objective cure in women with stress urinary incontinence

\begin{tabular}{llll}
\hline Objective cure & Cured & Improved & Failed \\
\hline Stress test & $18(81.81 \%)$ & $2(9.9 \%)$ & $2(9.9 \%)$ \\
Pad test & $18(81.81 \%)$ & $2(9.9 \%)$ & $2(9.9 \%)$ \\
\hline
\end{tabular}

Table 5: Comparison of age, duration of surgery, and blood loss in various studies

\begin{tabular}{lllll}
\hline & \multicolumn{5}{c}{$\begin{array}{l}\text { Duration } \\
\text { of surgery } \\
\text { in years }\end{array}$} & $\begin{array}{l}\text { Blood loss } \\
\text { (minutes) }\end{array}$ & $\begin{array}{l}\text { Cure rate } \\
(\%)\end{array}$ \\
\hline Taweel et al. $^{8}$ & $50 \pm 9$ & $18 \pm 4$ & 57 & 92 \\
Magon et al. $^{9}$ & 46.2 & 21.69 & 76.78 & 93.2 \\
Moore et al. $^{10}$ & 56.8 & 12.4 & 36 & \\
Purnichescu et al. $^{11}$ & & 23 & & \\
Present study & $44.8 \pm 4.2$ & $25 \pm 5$ & Average & 90.90 \\
\hline
\end{tabular}

Table 6: Comparison of complications in various studies

\begin{tabular}{llll}
\hline Study & $\begin{array}{l}\text { Vaginal } \\
\text { laceration (\%) }\end{array}$ & Groin pain (\%) & $\begin{array}{l}\text { Urinary } \\
\text { retention (\%) }\end{array}$ \\
\hline $\begin{array}{l}\text { Giberti et al. } \\
\text { Meschia et al. }\end{array}$ & 6.4 & & \\
Waltregny et al. $^{23}$ & & 5.0 & \\
Dobson et al. $^{24}$ & 9.6 & 26 & 4.0 \\
Delorme et al. $^{5}$ & & & 3.13 \\
Pankaj et al. & & & \\
Present study & 4.54 & 15.62 & 3.12 \\
\hline
\end{tabular}

\section{Discussion}

The TOT is a minimally invasive surgery for treatment of SUI. It has a high success rate as quoted in the literature and the total success rate of the transobturator sling in this study was also $90.90 \%$. Our objective assessment demonstrated $81.18 \%$ cure and $9.9 \%$ improvement rate after 6 months. (no apparent cause could be found for failure of surgery in these two cases.)

The subjective global satisfaction rate recorded at 6 months is $72.72 \%$ cure and $18.18 \%$ improvement. As is often the case, the rate of our subjective assessment is lower than the one observed during the objective clinical examination.

The overall objective and subjective cure rates were different in our study population. This result could be due to the fact that frequency or urge incontinence is not demonstrated on the stress test.

The TOT is effective and easy to perform; the retropubic placement of the suburethral tension-free vaginal tape has been associated with a number of perioperative and postoperative complications, including bowel, tape erosion, vascular, and bladder injuries. ${ }^{4,712}$ This reality encouraged urologists to adopt TOT, which has similar principles in treating SUI but with minimal morbidity.

In our series, we treated women of stress incontinence due to hypermobility and excluded women with intrinsic sphincter deficiency without hypermobility. None of our women had mixed or urge incontinence.

\section{Bladder Injuries}

There was no bladder or urethral injury in our study. In the Austrian TOT tape registry comprising of 2,541 TOT surgeries, 10 bladders and 2 urethral perforations are reported. ${ }^{13}$ In a retrospective study of 390 women treated with TOT, 2 urethral and 2 bladder injuries were reported in the study conducted by Abouassaly. ${ }^{14}$ Minaglia et al. ${ }^{15}$ recommend universal intraoperative cystoscopy when performing TOT especially in previous extensive pelvic surgery and when needle passage is difficult.

No urethral or bladder injury was noted or identified. After performing 390 cases of TOT by different routes, Abdel-Fattah and colleagues found that lower urinary tract injury occurred with the outside-in technique. Bladder injuries occurred in women who underwent concomitant vaginal surgery, while urethral injuries occurred in women undergoing secondary procedures. ${ }^{16}$ In a recent literature review by Sivanesan and colleagues, several cases of bladder injury were reported; they recommend cystoscopy in cases of associated pelvic surgery or presence of prolapse, previous retropubic surgery, or in cases where it is difficult to insert the tapes. Adverse events such as bladder injuries and voiding difficulties were less common. ${ }^{17}$

In our practice we are not considering cystoscopic examination, unless a complication is suspected. This results in shorter operative time and lower procedure cost.

\section{Voiding Problems}

Although urine retention and voiding dysfunction are thought to be less common after the transobturator approach, the rates vary from 0 to $15.6 \% .^{12}$ In our series, four (18.18\%) women developed urinary retention, which was transient, which was relieved in a day.

The highest obstruction-inducing risk is the surgeon himself tensioning the tape (it is supposed to be tension free) too much. In a patient with immediate postoperative retention or incomplete bladder emptying, an indwelling catheter or intermittent selfcatheterization is tried as a spontaneous resolution is common. A simple sling lysis is considered in a persistent voiding problem. Obstructive voiding has been reported to occur in $1.5-15.6 \%$ of women after a TOT.

\section{Hemorrhage}

Hemorrhage-related complications do occur in the TOT procedure in $1-2 \%$ of the cases and include heavy intraoperative bleeding, pelvic hematoma, retropubic hematoma, and perineal, labial, or thigh hematoma. ${ }^{13}$

\section{Vaginal Erosion}

Vaginal erosions are probably the result of inadvertent, unrecognized vaginal wall punctures during a TOT procedure and the contributing factors are tension between the mesh and vaginal epithelium, inadequate reapproximation of vaginal tissues, subclinical infections of the sling material, and impaired vascularity. Unrecognized, vaginal laceration may predispose women to mesh extrusion. We encountered one case of vaginal wall injury during the passage of the tunneler and it was reinserted again without any sequel. Therefore, it is highly recommended to inspect the lateral vaginal wall after passing the needle through the transobturator foramen. Deval ${ }^{18}$ reported incidence rates of vaginal erosions in TVT and TOT tapes as 0.7 and $13.8 \%$, respectively. Lathe et al. in a systematic review and meta-analysis of the effectiveness and complications following both the procedures reported the incidence of vaginal injuries or erosion of mesh (OR 1.96; $95 \% \mathrm{Cl} 0.87$ J Obsteas more common after tape insertion by the transobturator route. Vesicovaginal fistulas have also been reported after TOT surgeries. Recently, high rates of vaginal erosion have been seen in TOT procedures using URA Tape/Ob Tape. Siegel et al. ${ }^{19}$ reported a $20 \%$ vaginal extrusion in women with Ob Tape (TOT tape). 


\section{Groin Pain}

Laurikainen et al. ${ }^{20}$ in his comparison of 136 women in the TVT group with 131 women in the TOT group observed that groin pain is significantly more in TOT women than in TVT women (16\% vs $1.5 \%$ ) and considerably more opiate analgesia ( $21 \%$ vs $12 \%$ ) was needed in the TOT group. In a meta-analysis by Lathe et al. groin/thigh pain was less observed (OR 8.28; $95 \% \mathrm{Cl} 2.71$ women) $)^{15}$

The possible explanation is a path of insertion through the muscular or tendinous portion of the adductor muscles. Compression or entrapment of the anterior obturator nerve during the TOT procedure may also add to groin pain or exercise related pain.

Most important step to avoid erosion and voiding dysfunction was found to be tape adjustment without any tension or any contact with the urethra. We had three $(13.63 \%)$ women having groin pain in our series who required analgesics, which confirms recent findings of a meta-analysis that the outside-in technique is usually not associated with thigh pain.

Women with failure of the procedure were investigated and were advised for follow-up. About $90.90 \%$ women had improvement in the quality of life.

\section{Conclusion}

Stress urinary incontinence remains underdiagnosed and underreported affecting the social, emotional, and sexual life of a woman.

As per Cochrane meta-analysis, the transobturator tape is one of the best treatment available today.

Correct diagnosis and trial of conservative therapy should be considered before surgery. Of the MUSs, the transobtuator tapes have comparable success and satisfaction rates as the transvaginal tapes in uncomplicated, mild-to-moderate SUI, with reduced risk of intraoperative bladder injury, shorter operating time and quicker return to activities, and no need of cystoscopy. Thus, the transobturator tapes may be recommended as the primary choice for the surgical treatment of female SUI. Success of TOT depends upon suspension and support of the vesicourethral segment, proper selection of patients, and surgical expertise.

The limitations of our study was that the time period for which the women were followed up was 6 months and in view of the same any long-term morbidity or long-term satisfaction level of the women treated could not be recorded and analyzed. Hence, larger studies with long-term follow-up are required.

\section{References}

1. WS Reynolds, Dmochowski RR, Penson DF, et al. Epidemiology of stress urinary incontinence in women. Curr Urol Rep 2011;12(5): 370-376. DOI: 10.1007/s11934-011-0206-0.

2. Guidelines for surgical management for female stress urinary incontinence: update (2009) American Urology Association. 2009.

3. Hampel C, Weinhold D, Benken N, et al. Definition of overactive bladder and epidemiology of urinary incontinence. Urology 1997;50(6A Suppl):4-14. DOI: 10.1016/S0090-4295(97)00578-5.

4. Ulmsten U, Petros P. Intravaginal slingplasty (IVS): an ambulatory procedure for treatment of female urinary incontinence. Scand J Urol Nephrol 1995;29(1):75-82. DOI: 10.3109/00365599509180543.

5. Delorme E. Transobturator urethral suspension: mini invasive procedure in the treatment of stress urinary incontinence in women. Prog Urol 2001;11(6):1306-1313.

6. De Leval J. Novel surgical technique for the treatment of female stress urinary incontinence: transobturator vaginal tape inside-Out. Eur Urol 2003;44(6):724-730. DOI: 10.1016/j.eururo.2003.09.003.
7. DeTayrac R, Deffieux X, Droupy S, et al. A prospective randomized trial comparing tension-free vaginal tape and transobturator suburethral tape for surgical treatment of stress urinary incontinence. Am J Obstet Gynecol 2004;190(3):602-608. DOI: 10.1016/j.ajog.2003.09.070.

8. Taweel WA, Rabah DM. Transobturator tape for female stress incontinence: follow-up after 24 months. Can Urol Assoc J 2010;4(1):33-36. DOI: 10.5489/cuaj.08118.

9. Magon M, Chopra SV. Transobturator tape in treatment of stress urinary incontinence: it is time for a new gold standard. N Am J Med Sci 2012;4(5):226-230. DOI: 10.4103/1947-2714.95905.

10. Moore RD, Miklos JR, Transobturator Sling: Combined analyses of 1 year follow up in 9 countries with 266 patients: XV Congress of the International Society for Gynecologic Endoscopy. April 1, Argentina: Buenos Aires; 2006.

11. Purnichescu V, Cheret-Benoist A, Eboué C, et al. Surgical treatment for female stress urinary incontinence by transobturator tape (outside in). study of 70 cases. J Gynecol Obstet Biol Reprod (Paris) 2007;36(5):451-458. DOI: 10.1016/j.jgyn.2007.04.001.

12. Barber MD, Gustilo-Ashby AM, Chen CC, et al. Perioperative complications and adverse events of the monarc transobturator tape, compared with the tension-free vaginal tape. Am J Obstet Gynecol 2006;195(6):1820-1825. DOI: 10.1016/j.ajog.2006.07.007.

13. Tamussino K, Hanzal E, Kolle D, et al. Transobturator tapes for stress urinary incontinence: results of the austrian registry. Am J Obstet Gynecol 2007;197(6):634.e1. DOI: 10.1016/j.ajog.2007.08.018.

14. Abouassaly R, Steinberg JR, Lemieux M, et al. Complications of tension-free vaginal tape surgery: a multi-institutional review. BJU Int 2004;94(1):110-113. DOI: 10.1111/j.1464-410X.2004.04910.x.

15. Minaglia S, Ozel B, Klutke C, et al. Bladder injury during transobturator sling.Urology 2004;64(2):376-377. DOI: 10.1016/j.urology.2004.04.030.

16. Abdel-Fattah M, Ramsay I, Pringle S, et al. Transobturator suburethral tapes in the management of urinary incontinence: success, safety and impact on sexual life. Gynecol Surg 2007;4:267-273. DOI: 10.1007/ s10397-007-0303-8.

17. Latthe P, Foon R, Toozs-Hobson P. Transobturator and retropubic tape procedures in stress urinary incontinence: a systematic review and meta-analysis of effectiveness and complications. BJOG 2007;114(5):522-531. DOI: 10.1111/j.1471-0528.2007.01268.x.

18. Deval B, Ferchaux J, Berry R, et al. Objective and subjective cure rates after trans-obturator, tape (OBTAPE1) treatment of female urinary incontinence. Eur Urol 2006;49(2):373-377. DOI: 10.1016/ j.eururo.2005.11.012

19. Siegel AL. Vaginal mesh extrusion associated with use of mentor transobturator sling. Urology 2005;66(5):995-999. DOI: 10.1016/j. urology.2005.05.015.

20. Laurikainen E, Valpas A, Kivelä A, et al. Retropubic compared with transobturator tape placement in treatment of urinary incontinence: a randomised controlled trial. Obstet Gynecol 2007;109(1):4-11. DOI: 10.1097/01.AOG.0000249607.82768.a1.

21. Giberti C, Gallo F, Cortese P, et al. Transobturator tape for treatment of female stress urinary incontinence: objective and subjective results after a mean follow-up of two years. Urology 2007;69(4):703-707. DOI: 10.1016/j.urology.2007.01.013.

22. Meschia M, Pifarotti P, Bernasconi F, et al. Tension free vaginal tape: analysis of outcomes and complications in 404 stress incontinent women. Int Urogynecol J Pelvic Floor Dysfunct 2001;12(Suppl 2):S24-S27. DOI: 10.1007/s001920170008.

23. Waltregny D, Gaspar Y, Reul O, et al. TVT-for the treatment of female stress urinary incontinence: results of aprospective study after a 3-year minimum follow-up. Eur Urol 2008;53(2):401-410. DOI: 10.1016/j.eururo.2007.08.021.

24. Dobson A, Robert M, Swaby C, et al. Trans-obturator surgery for stress urinary incontinence: 1-year follow-up of a cohort of 52 women. Int Urogynecol J Pelvic Floor Dysfunct 2007;18(1):27-32. DOI: 10.1007/ s00192-006-0115-9.

25. Pankaj S, Singh M, Raghwendra KH, et al. An evaluation of use of tot in the current surgical management of female stress urinary incontinence. Int J Sci Study 2014;2(4):25-28. 